\title{
Counseling Teacher Quality Improvement: Upaya Meningkatkan Kualitas Hubungan Siswa dan Guru
}

\author{
Neila Ramdhani ${ }^{1,1}$ E Yuliardi Swasono ${ }^{2}$ \\ ${ }^{1}$ Fakultas Psikologi Universitas Gadjah Mada \\ ${ }^{2}$ Titian Foundation
}

\begin{abstract}
This article encompasses two studies about the influence of Counseling Teacher Quality Improvement (CTQI) Program in improving the competence of guidance and counseling teacher. The first study evaluated the effectiveness of CTQI in changing students and headmaster's perceptions toward the way guidance and counseling teacher facilitates students in managing their problems. The second study aimed to examine the increase of guidance and counseling teacher's counseling self-efficacy after participating in the three months counseling assistance program. Participants were 59 guidance and counseling teachers, 59 student groups, and 59 headmasters. Guidance and counseling teacher's selfperception scale was given to teachers, perception toward teacher scale was given to headmasters and students. Counseling self-efficacy scale was only given to teachers. Data analysis showed that the perception of teachers, headmasters, and students increased after teachers partook in CTQI. Improvement also occured in counseling self-efficacy after counseling assistance program. However, headmasters' perception toward guidance and counseling teachers' counseling self-efficacy remained unchanged.
\end{abstract}

Keywords : competence; counseling; self efficacy; teacher quality improvement

\begin{abstract}
Abstrak. Artikel ini memuat dua studi tentang pengaruh program Counseling Teacher Quality Improvement (CTQI) untuk meningkatkan kompetensi guru Bimbingan Konseling (BK). Studi 1 mengevaluasi efektivitas CTQI dalam mengubah persepsi siswa dan kepala sekolah terhadap cara guru BK memfasilitasi siswa mengelola permasalahan mereka. Studi 2 bertujuan menguji peningkatan efikasi diri konseling pada guru BK setelah mengikuti program 3 bulan pendampingan konseling. Partisipan penelitian adalah 59 guru BK, 59 kelompok siswa, 59 kepala sekolah. Skala persepsi diri guru BK (PDBK) disajikan kepada guru, Skala Persepsi terhadap guru BK (PBK) disajikan kepada kepala sekolah dan siswa. Skala Efikasi Diri Konseling (SEDK) hanya disajikan kepada guru. Analisis data memperlihatkan bahwa persepsi guru, kepala sekolah, dan siswa meningkat setelah guru mengikuti pelatihan CTQI. Peningkatan juga terjadi pada efikasi diri konseling guru setelah mereka mengikuti pendampingan konseling. Namun demikian, persepsi kepala sekolah terhadap efikasi diri konseling guru BK tidak mengalami perubahan.
\end{abstract}

Kata kunci : efikasi diri; kompetensi; konseling; teacher quality improvement

Perilaku anti sosial yang dilakukan siswa sekolah semakin meningkat, baik dari segi kuantitas maupun ragamnya.
Sebagai contoh, perkelahian antar siswa di Jakarta di penghujung 2012, membunuh seorang siswa Sekolah

\footnotetext{
1 Korespondensi mengenai isi artikel ini dapat dilakukan melalui neila_psi@ugm.ac.id
} 
Menengah Atas (SMA) (Pertiwi \& Cipta, 2012). Kasus lain berupa tawuran antar sekolah terjadi di Watampone, Sulawesi Selatan melibatkan ratusan siswa (Agustina, 2013). Berita menyedihkan ketika seorang siswi Sekolah Menengah Pertama (SMP) tewas bunuh diri semata karena gagal dalam ujian nasional (Sasongko, 2014). Dunia pendidikan Indonesia serasa semakin mencekam ketika media memberitakan meninggalnya seorang siswa ditikam teman sendiri (Rofiq, 2014), pertarungan ala gladiator dilakukan siswa Sekolah Dasar (SD) yang berujung seorang siswa tewas dalam kondisi yang sangat mengenaskan (Bempah, 2017), dan peristiwa tragis yang amat memilukan di awal tahun 2018 adalah seorang siswa memukul hingga gurunya meninggal dunia.

Berbagai peristiwa itu merupakan alarm tanda bahaya yang menimbulkan pertanyaan terkait dengan hubungan antara siswa dan guru, khususnya guru bimbingan konseling (BK). Apakah siswa sekolah merasakan keberadaan guru BK mereka sebagai agen yang siap sedia membantu mereka pada saat menghadapi masalah? Bukankah guru tidak hanya berperan mendampingi siswa dalam hal persoalan akademik tetapi juga perkembangan sosialnya (Rimm-kaufman \& Sandilos, 2011)? Aktualisasi peran guru BK di sekolahsekolah Indonesia masih menjadi pertanyaan bila dikaitkan dengan berbagai peristiwa kenakalan dan kekerasan yang cenderung menjadi perilaku kriminal yang dilakukan remaja usia sekolah. Tulisan ini didasarkan kepada studi eksperimental kuasi yang menguji perubahan persepsi siswa dari 59 sekolah terhadap guru BK mereka yang mengikuti program CTQI yang dikembangkan oleh Ramdhani dan Ancok (2013).

Persepsi siswa terhadap hubungan guru-siswa sangat penting untuk menumbuhkan motivasi intrinsik siswa dan academic self regulation (Raufelder, Scherber, \& Wood, 2016). Pentingnya persepsi positif siswa terhadap hubungan guru-siswa ini juga dilaporkan menghindarkan victimization siswa oleh teman-temannya (Lucas-Molina, Williamson, Pulido, \& Perez-Albeniz, 2015; Sulkowski \& Simmons, 2018). Hal ini dapat terjadi karena rasa aman dan nyaman terhubung dengan guru membuat siswa merasa kompeten, sebagai konsekuensinya autonomous self regulation dapat tumbuh (Niemiec \& Ryan, 2009).

Kondisi sebaliknya terjadi jika guru BK dianggap sebagai stimulus aversive, sehingga berlaku hukum di dalam pendekatan perilakuan di mana siswa akan menghindar dari guru BK walaupun sebetulnya mereka sangat membutuhkan tempat untuk mengungkapkan berbagai kegusaran terkait dengan permasalahan mereka sebagai remaja. Peristiwa tawuran antar siswa, jual-beli soal dan jawaban ujian nasional, hingga bunuh diri yang terjadi adalah contoh dari jalan pintas yang ditempuh siswa dapat menjadi akibat dari ketiadaan tempat untuk berbagi rasa. Peran guru BK di sekolah masih dipandang sebagai eksekutor hukuman yang diberikan kepada siswa atau sering disebut 'polisi sekolah' yang ditakuti. Hal ini tidak dapat disangkal karena berdasarkan studi preliminari yang dilakukan peneliti, guru BK sendiri masih merasa kurang yakin tentang kompetensi mereka di sekolah. Konsep kekurangyakinan guru BK atas kompetensi, di dalam tulisan ini mengacu kepada counseling teacher self-efficacy diintervensi dengan program CTQI (Ramdhani \& Ancok, 2013), yang didesain khusus untuk guru BK. 


\section{Counseling self-efficacy}

Konsep self-efficacy digunakan untuk menggambarkan tentang ability to achieve desired levels of performance dari seseorang (Bandura, 1995). Counseling self efficacy (CSE) secara spesifik menunjuk kepada keyakinan seseorang konselor mengenai kemampuannya melakukan kegiatan konseling (Larson \& Daniels, 1998). CSE ini sangat penting dimiliki oleh seorang konselor untuk dapat meningkatkan efektivitas dalam melakukan konseling (Schiele, Weist, Youngstrom, Stephan, \& Lever, 2014). CSE memengaruhi persepsi konselor terhadap berat atau ringannya tugas yang diemban dan karakteristik atasan (Larson \& Daniels, 1998). Also, CSE berhubungan positif dengan evaluasi diri, sehingga kecemasan konselor terhadap kinerjanya juga menurun (Larson \& Daniels, 1998). Konsekuensinya, CSE memberikan hasil positif yang lebih banyak untuk klien.

Pentingnya CSE ini mendorong beberapa peneliti untuk mengungkap faktor psikologis yang memengaruhinya, diantaranya pendidikan dan training dalam bidang konseling, social desirability, kepribadian konselor, aptitude, achievement (Larson \& Daniels, 1998), afek positif (Ümmet, 2017), emotional intelligence (Easton, Martin, \& Wilson, 2008), mastery experience (Ooi, Wan Jaafar, \& Baba, 2015), dan pengalaman kerja sebagai konselor (Melchert, Hays, Wiljanen, \& Kolocek, 1996; Tang et al., 2004). Peran masing-masing variable tersebut terhadap CSE bervariasi dari yang lemah hingga kuat.

Riset yang dilakukan oleh Melchert et al. (1996) dan Larson and Daniels (1998) mengungkapkan bahwa ragam pendidikan dan pelatihan yang diikuti seorang konselor secara signifikan menentukan CSE. Akan tetapi, riset yang dilakukan oleh Tang et al. (2004) memperlihatkan bahwa hubungan prediktif ini tidak terbukti. Hubungan pengaruh pengalaman melakukan konseling dengan CSE semakin melemah pada konselor yang sudah menyelesaikan pendidikan master dalam bidang konseling (Larson, Cardwell, \& Majors, 1996; Melchert et al., 1996). Ketidakkonsistenan temuan ini meng-undang peneliti untuk merancang sebuah model training yang dapat meningkatkan CSE.

Beberapa peneliti sudah melakukan penelitian mengenai metode untuk meningkatkan CSE. Salah satunya dilakukan dengan metode role play dan rekaman video (Larson et al., 1999). Dalam penelitiannya, Larson et al menemukan bahwa evaluasi diri mengenai keberhasilan dalam menjalani sesi menjadi moderator dari hubungan antara persepsi akan sukses dengan kualitas skenario dari kegiatan role play. Metode lain yang juga digunakan untuk meningkatkan CSE adalah training tentang keterampilan khusus untuk melakukan konseling (Urbani et al., 2002). Sedangkan, Reese et al., (2009) mengemukakan bahwa feedback menjadi penentu dari CSE.

Penelitian ini bertujuan untuk meningkatkan keterampilan konseling para guru BK. Dengan mengacu bahwa seorang konselor terlebih dahulu harus matang dan cerdas emosinya (Easton et al., 2008) maka fondasi awal dari modul pelatihan ini adalah kecerdasan emosi diikuti dengan keterampilan konseling (Urbani et al., 2002).

\section{Counseling teacher quality improvement}

Program peningkatan kualitas guru yang dirancang khusus untuk meningkatkan kompetensi guru-guru BK ini merupakan modifikasi dari TQI (Ramdhani \& Ancok, 2013; Ramdhani, Ancok, Swasono, \& Suryanto, 2012) yang disusun secara sistematis untuk memfasilitasi perubahan sikap guru dalam menjalankan tugasnya. 
Program TQI disusun dengan mendasarkan kepada teori psikologi positif bahwa manusia itu pada dasarnya menginginkan kehidupan yang positif, yaitu pleasant life, engaged life, dan meaningful life. Guru dapat mencapai pleasant life bila ia mengenali sebanyak mungkin emosi positif kemudian berlatih untuk mengembangkan bagi dirinya sendiri agar dapat menjadi contoh bagi siswanya. Engaged life dapat dicapai bila guru mengenali bagian positif dari dirinya kemudian menggunakannya untuk bekerja dan membangun hubungan dengan orang lain. Bagi guru, keterampilan membangun hubungan ini penting dalam mendidik anak-anak di sekolah. Meaningful life dapat dicapai bila dalam menjalankan profesinya membangun institusi sekolah lebih memfokuskan kepada emosi dan sifat individu yang positif sehingga karakter positif dapat terbentuk (Seligman, 2004). Meaningful life tercermin dari sikap kerja yang tulus sehingga guru bekerja bukan hanya karena ia bekerja sebagai guru yang menerima gaji melainkan ia ingin memberikan makna bagi hidupnya ketika mengetahui pengetahuan dan sikap positif siswa meningkat sehingga dapat menjadi insan yang berguna bagi bangsanya.

Di dalam kerangka kecerdasan emosi, pengenalan emosi dan sifat individu yang positif ini adalah kompetensi personal sedangkan penggunaannya di dalam membangun hubungan dengan orang lain adalah kompetensi sosial (Goleman, 2005). Beberapa riset melaporkan ada keterkaitan antara kecerdasan emosi dengan prestasi, produktivitas, kepemimpinan, dan kesehatan (Epstein, 1998; Goleman, 2000, 2005; Low \& Nelson, 2005; Nelson \& Low, 2003). Ketiga kompetensi ini sangat penting sebagai dasar pengembangan kompetensi pedagogi bagi guru BK yaitu (1) memahami secara mendalam siswa yang dilayani, (2) menguasai landasan dan kerangka teoretik bimbingan dan konseling, (3) menyelenggarakan pelayanan bimbingan dan konseling yang memandirikan, dan (4) mengembangkan pribadi dan profesionalitas konselor secara berkelanjutan (Ramdhani, 2012).

Modul pelatihan CTQI dikembangkan berdasarkan kepada temuan Sutton dan Wheatley (2003) bahwa guru yang cerdas emosinya dapat memperlakukan siswa dengan menyenangkan, dan mampu membuat siswanya menikmati proses belajar di setiap mata pelajaran. Mekanisme rasa senang siswa terhadap guru yang menyenangkan ini dipaparkan oleh Clore dan Byrne (1974) dalam The Reinforcement Affect Model. Guru yang cerdas emosinya dan tampil menyenangkan akan dipersepsi siswa secara positif sehingga materi pembelajaran maupun pesan pendidikan lainnya yang dibawa oleh guru tersebut akan direspons dengan positif pula. Eggleton (1992) menyatakan bahwa guru yang mampu memotivasi dapat menstimulasi motivasi intrinsik siswa untuk belajar. Demikian pula halnya dengan kreativitas, guru kreatif membuat siswa bergairah dalam belajar (Ramdhani \& Ancok, 2013).

Beberapa hal ikut diperhitungkan untuk meningkatkan peluang keberhasilan program ini. Belajar dari Kotter's organizational change model, program CTQI diawali dengan beberapa kegiatan: (1) seminar dengan topik 'New Paradigm in Learning' diselenggarakan untuk kepala sekolah dan pengawas sekolah. Seminar ini dilakukan untuk meningkatkan buy-in terhadap program dan menimbulkan sense of urgency pemimpin sekolah. Workshop 'Kepemimpinan Sekolah' untuk para kepala sekolah yang sudah menyatakan diri bersedia bekerja sama 
dengan tim peneliti. Workshop yang dilaksanakan selama 5 hari dengan waktu 8 jam/hari bertujuan untuk memberikan wawasan kepada kepala sekolah mengenai pentingnya pengembangan kompetensi guru dalam konteks manajemen berbasis sekolah. (3) Sosialisasi kepada semua warga sekolah mengenai program CTQI, khususnya guru BK. Sosialisasi selama 2 jam ini dilakukan agar semua guru di sekolah mendapatkan informasi mengenai program CTQI. Rekan kerja yang mempunyai pemahaman yang sama tentang kegiatan yang dilakukan guru BK diharapkan dapat menjadi social reinforcement bagi guru BK. Di akhir sosialisasi, dilakukan rekrutmen peserta yang bersedia mengikuti pelatihan CTQI.

(4) Pelaksanaan pelatihan in-house dilakukan selama 10 hari atau ekuivalen dengan 80 jam pelatihan. Pelatihan dirancang sedemikian rupa sehingga dapat memperkuat kompetensi guru BK.

(5) Supervisi terhadap guru ketika mereka mengimplementasikan keterampilan yang diperoleh selama pelatihan in-house di sekolah. Supervisi yang diakukan didasarkan kepada integrated developmental model (Stoltenberg \& McNeill, 2011). Pendampingan ini diakukan selama 3 bulan, sekali setiap dua minggu dengan durasi 2 jam, ekuivalen with 15 jam supervisi. (6) Di akhir program CTQI ini, dilakukan Seminar bekerja sama dengan Kementerian Pendidikan dan Kebudayaan (Kemendikbud), untuk memberikan reinforcement kepada semua peserta bahwa peningkatan kompetensi mereka mendapat acknowledgement dari Kemendikbud. Anchoring new approaches in culture yang dilakukan dengan cara memberikan reinforcement kepada sekolah yang sudah berhasil mengimplementasikan paradigma baru dalam pembelajaran.

Tabel 1 memperlihatkan pembandingan beberapa langkah yang sudah dilakukan oleh program CTQI sebelum memulai intervensi kepada guru BK dengan delapan langkah perubahan yang dikemukakan oleh Kotter (1996). Beberapa langkah Kotter itu tidak dilakukan karena sasaran perubahan lebih kepada pola pikir dan perilaku guru di sekolah.

Tabel 1.

Perbandingan Kotter's 8 Steps of Change dan Program CTQI

\section{Tahap Delapan tahap Kotter's change}

$1 \quad$ Establish sense of urgency

2 Build guiding team

3 Develop the vision

4 Communicate for buy-in

5 Empower action

$6 \quad$ Create short team wins

7 Don't let up

8 Make change stick/anchoring new behavior in the culture
Program CTQI

Penumbuhan kebutuhan akan perubahan:

Seminar untuk Kepala Sekolah

Menyiapkan pendamping yang dapat mendukung proses perubahan: Workshop

Kepala Sekolah dan Pengawas Sekolah

Sosialisasi kepada semua warga sekolah

Pelatihan CTQI

Pendampingan konseling

Seminar Best Practice in CTQI

Implementation 
Metode penyampaian materi yang digunakan dalam program CTQI adalah experiential learning yang terbukti di beberapa penelitian memfasilitasi pertumbuhan mental dan kematangan (Kolb, 1984; Silberman, 2007). Experiential learning memungkinkan individu memperoleh kesempatan belajar yang lebih banyak karena mereka terlibat di dalam pengalaman nyata (Brown \& Harvey, 2006), berupa modelling, baik in vivo maupun video, diskusi kasus, role play, latihan, permainan, simulasi, maupun ceramah. Setelah melakukan aktivitas, trainer atau fasilitator melakukan debrief. Sebagian literatur menyebutnya dengan debriefing (Greenaway, 2007) di mana trainer atau fasilitator memfasilitasi keterlibatan peserta untuk menyadari, aktif terlibat, dan memperoleh pemahaman atau makna dari berbagai pengalaman yang dijalani. Di dalam kelompok, partisipan membuat kesimpulan pembelajaran baik pada level kognitif, efektif, dan psikomotorik. Disini mulai terjadi penguatan beliefs bagi individu tentang kemampuannya untuk melakukan suatu perilaku tertentu sehingga mereka akan lebih berani melakukan apa yang telah mereka pelajari.

Kerangka pikir dan hipotesis penelitian

Pengetahuan dan keterampilan seorang guru BK sangat penting namun selfefficacy seorang guru BK yang termanifestasi dalam bentuk keyakinan bahwa ia dapat melakukan tugasnya dengan baik sangat memengaruhi keberhasilan guru BK dalam melakukan tugasnya. Sumber self-efficacy adalah mastery experience, vicarious experience, social persuassion, dan physiologis state. Pelatihan in-class CTQI terdiri dari kompetensi kepribadian, sosial, dan pedagogis. Kompetensi kepribadian dan sosial memberikan kesempatan kepada guru BK untuk mengenali dan mengelola emosi diri dan orang lain sedangkan kompetensi pedagogis memberikan pengetahuan dan keterampilan untuk melaksanakan tugas sebagai guru BK. Pengenalan emosi diri dan orang lain ini menjadikan guru BK lebih dapat menerima dirinya, menyadari kebermaknaan profesi sebagai guru BK. Modul pedagogis merupakan penyegaran bagi guru BK tentang keterampilan yang harus ditingkatkan sehingga dapat memberikan layanan kepada siswa dengan lebih baik. Dengan meningkatkan keterampilan konseling ini guru merasa lebih nyaman dengan dirinya sehingga mereka dapat tampil lebih tulus dan menyenangkan di hadapan siswa maupun rekan kerjanya.

Selama proses pelatihan in-class CTQI, guru BK berlatih, menerima feedback, berdiskusi, dan menyaksikan pengalaman rekan sesama peserta pelatihan pada saat berlatih di dalam kelompok. Di sini, trainer memanfaatkan metode experiential learning untuk memberi feedback, debriefing, memandu guru BK sharing emosi dan pengalaman kemudian mendiskusikan dengan rekan sesama peserta. Pengalaman ini menjadi sumber penguat self-efficacy bagi guru BK. Selesai mengikuti pelatihan in-class CTQI guru BK peserta pelatihan disupervisi untuk mengimplementasikan keterampilan yang mereka peroleh selama pelatihan. Mengacu kepada penelitian yang dilakukan oleh (Leach, Stoltenberg, Moneill, \& Eichenfield, 1997), integrated developmental model supervision diterapkan untuk meningkatkan efikasi diri konseling guru BK.

Kerangka pemikiran ini diuji melalui dua studi. Studi satu bertujuan untuk menguji efektivitas pelatihan CTQI dalam meningkatkan persepsi guru, siswa, dan kepala sekolah terhadap kompetensi guru BK. Tiga hipotesis pada 
studi 1 adalah: 1) persepsi guru BK terhadap kompetensi mereka meningkat setelah mengikuti pelatihan CTQI; 2) persepsi kepala sekolah terhadap guru BK menjadi lebih baik setelah guru mengikuti pelatihan CTQI; dan 3) persepsi siswa terhadap kompetensi guru BK menjadi lebih baik setelah guru mengikuti pelatihan CTQI.

Studi 2 dilakukan untuk mengungkap efektivitas supervisi untuk meningkatkan efikasi diri konseling guru-guru BK yang mengikuti tahap supervisi selama 3 bulan dengan hipotesis efikasi diri konseling guru BK sesudah mengikuti pedampingan CTQI lebih tinggi daripada sebelum mengikuti pendampingan CTQI.

\section{Metode}

\section{Partisipan}

Lima puluh sembilan guru BK yang berasal dari 59 sekolah, 59 kelompok siswa, dan 59 kepala sekolah berpartisipasi di dalam studi. Mereka berasal dari sekolah yang sudah bekerja sama untuk menyelenggarakan kegiatan penelitian ini. Guru BK secara sukarela menyatakan bersedia berpartisipasi setelah mendengarkan penjelasan tentang program CTQI dan memperoleh izin dari kepala sekolah. Di antara 59 guru, 44 orang perempuan sedangkan sisanya laki-laki. Usia mereka bervariasi antara 23-58 tahun. Pengumpulan data pre-test dilakukan pada hari pertama sebelum sesi pelatihan dimulai. Selama mengikuti pelatihan in-class, guru mendapatkan fasilitas menginap dan makan tiga kali sehari, buku bacaan 'Menjadi Guru Inspiratif', sebuah T-shirt, bahan pelatihan secara cuma-cuma, dan uang transportasi.

\section{Instrumen pengukuran}

Tiga instrumen pengukuran digunakan di dalam penelitian ini: 1) skala persepsi diri guru BK (PDBK) disajikan kepada guru; 2) skala persepsi terhadap guru BK (PBK) disajikan kepada kepala sekolah dan siswa; dan 3) skala efikasi diri konseling (SEDK) hanya disajikan kepada guru. Skala pertama, yaitu PDBK menggunakan skala yang sudah diuji pada riset terdahulu (Ramdhani et al., 2012) masing-masing terdiri dari 3 aitem mengungkap motivasi guru, penguasaan guru terhadap materi, dan keterampilan guru di kelas. Skala ini memberi kesempatan guru memberi skor 1-100 untuk setiap aitem, dengan reliabilitas Cronbach's $\alpha=0,923$. PBK yang disajikan kepada kepala sekolah dan siswa terdiri dari 7 aitem, mengungkap motivasi guru dalam membuat siswa merasa nyaman di sekolah, penguasaan guru BK mengenai teknik membantu siswa dalam mengelola permasalahannya, dan keterampilan guru dalam memotivasi siswa belajar. PBK ini dilengkapi dengan pilihan 1-3, dengan Cronbach's $\alpha=0,772$. Skala efikasi diri konseling (SEDK) merupakan skala yang disusun berdasarkan konsep teacher self efficacy yang dikemukakan Bandura (2006) yang terdiri dari efikasi dalam memengaruhi pengambil keputusan, efikasi diri dalam menyajikan pembelajaran, efikasi diri dalam kedisiplinan, efikasi diri dalam melibatkan orang tua, efikasi diri dalam melibatkan komunikas, dan efikasi diri dalam membangun iklim sekolah yang positif. SEDK terdiri dari 31 item, disusun dalam format skala likert dengan pilihan jawaban 1-5 sehingga skor SEDK yang akan diperoleh partisipan penelitian antara 31-155 dengan rerata skor 93. Skor tinggi mencerminkan seorang guru yang mempunyai keyakinan dapat melakukan tugas sebagai seorang guru BK. Reliabilitas SEDK sudah diuji dengan testretest reliability dengan Cronbach's $\alpha=$ 0,91 . 
Desain penelitian

Penelitian ini adalah penelitian eksperimen kuasi dengan desain non- random one group pretest - posttest design. Rancangan penelitian sebagaimana terlihat pada Tabel 2.

Tabel 2.

Rancangan Eksperimen

Studi Pre-test Treatment 1 Post-test 1/Pre-test 2 Treatment 2 Post-test 2

\begin{tabular}{lccccc}
\hline Studi 1 & O-1.1 & X1 & O-1.2 & - & - \\
\hline Studi 2 & - & - & O-2.1 & X2 & O-2.2 \\
\hline
\end{tabular}

Keterangan:

O-1 : Pengukuran pre-test 1 dengan PDBK, PBK (Kepala Sekolah) dan PBK (Siswa)

O-1.2 : Pengukuran post-test 1 dengan PDBK, PBK (Kepala Sekolah) dan PBK (Siswa)

O-2.1 : Pengukuran pre-test 2 dengan SEDK

O-2.2 : Pengukuran post-test dengan SEDK, PBK (Kepala Sekolah) dan PBK (Siswa)

$\mathrm{X} 1 \quad$ : CTQI in-class training selama 12 hari

X2 : Pendampingan konseling di sekolah selama 3 bulan

\section{Pelatihan CTQI}

Pelatihan CTQI terdiri dari tiga modul utama, yaitu kompetensi kepribadian, sosial, dan pedagogi. Modul ini dikembangkan oleh peneliti dengan dibantu para pakar dalam bidang psikologi dan pendidikan. Modul ini merupakan bagian dari modul CTQI (Ramdhani \& Ancok, 2013) yang dikembangkan khusus untuk guru BK, disusun didasarkan kepada konsep dan teori yang menyatakan bahwa belajar meliputi tiga domain yaitu kognitif, afektif, dan psikomotor yang dikemukakan Bloom (Anderson \& Krathwol, 2000).

Modul program CTQI meliputi materi-materi presentasi, lembar kerja, video, dan permainan, yang digunakan sebagai media pembelajaran untuk menstimulasi terjadinya pemahaman diri berdasarkan pengalaman (Harvey et al., 2008). CTQI disajikan selama 10 hari, ekuivalen dengan 80 jam pelatihan. Lima hari pertama mencakup modul kepribadian dan sosial, dilanjutkan dengan lima hari kedua untuk modul pedagogi. Sebelum disajikan kepada guru-guru BK, modul sudah diujicobakan kepada dua training batches dengan jumlah peserta 63 orang guru (Ramdhani et al., 2012).

\section{Pendampingan konseling}

Pendampingan (supervision) adalah kegiatan yang dilakukan oleh para pendamping sebaya yang sudah lebih paham (the more able peers) kepada partisipan. Dalam kegiatan ini, seorang pendamping melakukan sharing pengetahuan dan pengalaman konselingnya kepada guru yang sedang membangun dan memantapkan keterampilan konselingnya. Aktivitas pendampingan ini yang dilakukan di dalam penelitian ini mengacu kepada Integrative Developmental Model (IDM) (Stoltenberg \& McNeill, 2011). Dalam program pengembangan kompetensi guru BK ini, pendampingan dilakukan oleh para trainer terlatih, 2-3 jam setiap dua minggu selama 3 bulan.

Sesuai dengan pendekatan IDM, materi pendampingan disepakati bersama antara pendamping dan guru-guru BK yang didampingi, disesuaikan dengan 
tingkat kematangan berproses yang telah dialami oleh guru BK. Pada tingkat novice, partisipan memiliki keterampilan yang masih terbatas sehingga pendamping perlu lebih banyak memberikan arahan kepada guru BK. Dengan meningkatnya keterampilan guru BK maka pendamping memainkan perannya cukup sebagai pemberi penguat. Sebagai usaha memberikan pemaknaan dari adanya peningkatan keterampilan konseling bagi guru $\mathrm{BK}$, di akhir proses pendampingan dilakukan debrief.

Prosedur

Pada awal studi 1, partisipan terlebih dahulu mendapat penjelasan mengenai CTQI, baik tujuan, isi pelatihan, trainer, maupun jangka waktu pelaksanaan. Setelah partisipan menyatakan bersedia mengikuti pelatihan, peneliti mengirimkan surat permohonan izin kepada kepala sekolah dengan pertimbangan kemudahan implementasi di sekolah.

Pre-test dilakukan pada hari pertama pelaksanaan pelatihan. PDBK disajikan langsung kepada partisipan di hari pertama pelaksanaan pelatihan. Pada hari yang sama, dilakukan pengumpulan data PBK di sekolah masing-masing partisipan oleh tim pengambilan data yang sudah dilatih terlebih dahulu. PBK disajikan kepada kepala sekolah dan tiga orang siswa. Pengumpulan data persepsi siswa dan persepsi kepala sekolah terhadap guru BK ini dilakukan selama guru BK berada di lokasi pelatihan untuk menghindari bias.

Pelaksanaan pelatihan CTQI dilakukan di sebuah ruangan training yang memungkinkan trainer mengubah setting ruang sesuai dengan tujuan dari setiap aktivitas yang dilakukan. Kursi dan meja yang digunakan ringan sehingga mudah dipindah sehingga peserta dapat bergerak leluasa mengingat pelatihan ini menggunakan metode experiential learning. Di hari terakhir pelatihan, semua partisipan diminta untuk mengisi skala untuk mengukur post-test. Sedangkan, pengukuran post-test PBK untuk kepala sekolah dan siswa dilakukan antara tiga hingga empat minggu setelah guru mulai beraktivitas kembali. Hal ini dilakukan untuk memberikan kesempatan kepada siswa dan kepala sekolah berinteraksi dengan guru BK mereka.

Studi 2 dilakukan satu bulan setelah studi 1 selesai. Sebagaimana studi 1, partisipan studi 2 juga mendapat penjelasan dan membuat kesepakatan tentang keikutsertaan dalam program pendampingan guru BK. Kesepakatan ini sangat penting, baik untuk memelihara komitmen guru untuk mengimplementasikan keterampilan konseling pada saat memberikan layanan kepada siswa. Untuk meningkatkan kontekstualitas, keunikan permasalahan sekolah, serta mempermudah transportasi peserta ke lokasi, kegiatan supervisi dilakukan di salah satu sekolah dengan peserta guruguru yang mengajar di beberapa sekolah yang saling berdekatan. Supervisi dilakukan selama 2 jam, sekali tiap dua minggu selama 3 bulan. Aktivitas supervisi berbasis IDM ini fokus kepada implementasi keterampilan konseling, keterampilan asesmen dasar, teknik komunikasi terapeutik, dan diskusi tentang rencana pengembangan karir siswa. Pada saat partisipan melakukan kegiatan di dalam kelas, pendamping atau fasilitator sit-in mengamati dan memberi feedback.

Pre-test studi tahap 2 dilakukan untuk mengukur efikasi diri konseling dengan skala SEDK. Post-test dilakukan setelah periode pendampingan selesai, yaitu di akhir bulan ketiga.

\section{Hasil}


Pelatihan CTQI in-class dan persepsi terhadap kompetensi guru BK

Tabel 3 memperlihatkan data deskriptif yang diperoleh dari skala PBK dan PDBK. Sebelum mengikuti pelatihan, guru peserta pelatihan memersepsi kompetensi yang mereka miliki dalam menjalankan tugas sebagai guru BK ada pada tingkat cukup baik $($ mean $=166,41)$ dibandingkan dengan rerata hipotetik $(\mu=200)$. Setelah mengikuti pelatihan, persepsi guru terhadap kompetensi mereka melonjak jauh ke atas, dengan mean $=255,88$. Ada perbedaan yang signifikan antara persepsi guru terhadap kompetensi mereka sebelum dan sesudah mengikuti pelatihan $\mathrm{t}(57)=16,25 ; \mathrm{p}=0,01$. Dengan hasil ini, hipotesis 1 penelitian terbukti.

Tabel 3.

Perbandingan persepsi kepala sekolah dan siswa terhadap kompetensi guru BK sebelum dan sesudah pelatihan CTQI $(n=59)$

\begin{tabular}{llrrr}
\hline \multirow{2}{*}{ Statistik } & Waktu & \multicolumn{3}{c}{ Persepsi terhadap kompetensi guru BK } \\
\cline { 3 - 5 } & & Guru & Kepala sekolah & \multicolumn{1}{c}{ Siswa } \\
\hline Min skor & Pre-test & 79 & 17 & 8 \\
& Post-test & 185 & 18 & 12 \\
Maks skor & Pre-test & 245 & 27 & 20 \\
& Post-test & 300 & 28 & 21 \\
Mean (SD) & Pre-test & $166.41(45.45)$ & $22.25(1.94)$ & $14.21(2.14)$ \\
& Post-test & $255.88(28.15)$ & $22.79(2.12)$ & $16.85(1.95)$ \\
t-test & post-pre & $16.251^{* *}$ & $2.22 *$ & $7.03^{* *}$ \\
\hline
\end{tabular}

Keterangan: ${ }^{*}$ significant $5 \%$; ${ }^{* *}$ significant $1 \%$

Tabel 3 juga memperlihatkan bahwa persepsi kepala sekolah terhadap kompetensi guru BK sebelum pelaksanaan CTQI dapat dimasukkan dalam kategori cukup (mean $=22,25$ ) dibandingkan dengan mean hipotetik $(\mu$ $=20)$. Data yang dikumpulkan tiga minggu setelah pelaksanaan CTQI memperlihatkan adanya peningkatan persepsi kepala sekolah ini dengan mean $=$ 22,$79 ; \mathrm{t}(57)=2,22 \quad(\mathrm{p}=0,03)$. Hipotesis 2 penelitian terbukti.

Perubahan lain yang ditemukan dari penelitian ini adalah perubahan persepsi siswa terhadap kompetensi guru BK. Pada pengukuran sebelum CTQI dimulai, persepsi siswa terhadap guru BK pada level cukup (mean $=14,21$ ) dibandingkan dengan mean hipotetik $(\mu=$ 14). Tiga minggu setelah guru selesai mengikuti CTQI, persepsi siswa meningkat signifikan menjadi 16,$69 ; \mathrm{t}(57)$ $=7,06(\mathrm{p}=0,00)$. Hipotesis 3 penelitian ini pun terbukti.

Peningkatan persepsi diri dan persepsi orang lain terhadap sikap dan perilaku guru BK setelah mengikuti pelatihan in-class memberikan keyakinan kepada peneliti bahwa CTQI yang diberikan efektif untuk meningkatkan kompetensi mereka dalam melakukan tugas sebagai guru BK. Dengan persepsi diri yang sudah lebih positif ini, guru BK sudah lebih siap menjalankan tugas sebagai konselor. Integrated developmental model of supervision dilakukan untuk menumbuhkan keterampilan guru BK dalam memberikan konseling.

Efikasi diri konseling guru BK paska pendampingan 
Efikasi diri konseling dari guru-guru diukur satu bulan setelah guru mengikuti pelatihan CTQI. Pengukuran ini dilakukan untuk mengetahui keyakinan guru BK terkait implementasi pengetahuan dan keterampilan konseling yang diperoleh selama proses pelatihan. Sebelum proses supervisi dimulai rerata skor $\operatorname{SEDK}=61,69$ jauh lebih rendah dibandingkan dengan rerata hipotetik yaitu 93. Proses pendampingan yang diikuti dengan sungguh-sungguh oleh guru BK dapat meningkatkan efikasi diri konseling mereka menjadi 96,08. Peningkatan yang signifikan secara statistik dengan $\mathfrak{t}(57)=7,56 ; \mathrm{p}=0.00$ (Tabel 4) membuktikan bahwa hipotesis 4 dapat diterima.

Data lain yang digunakan untuk melihat peningkatan efikasi diri konseling guru BK ini adalah persepsi siswa dan kepala sekolah terhadap kompetensi guru BK setelah melalui proses pendampingan selama tiga bulan. Tabel 4 memperlihatkan bahwa persepsi guru BK terhadap peningkatan efikasi diri konseling selaras dengan persepsi siswa terhadap kompetensi guru BK dengan $t(57)=3,07 ; \quad p=0,01$. Namun demikian, kepala sekolah tidak melihat adanya peningkatan kompetensi guru BK setelah mengikuti proses pendampingan ini $\mathrm{t}(57)=0,18$; n.s.

Tabel 4.

Perubahan Efikasi Diri Konseling Guru BK Sebelum dan Sesudah Pendampingan ( $n=59)$

\begin{tabular}{llrrr}
\hline Statistik & Waktu & $\begin{array}{c}\text { Efikasi diri } \\
\text { konseling }\end{array}$ & \multicolumn{2}{c}{ Persepsi terhadap kompetensi guru BK } \\
\cline { 4 - 5 } Min skor & Pre-test & 29 & 18 & Kepala sekolah \\
& Post-test & 35 & 17 & Siswa \\
Maks skor & Pre-test & 99 & 28 & 12 \\
& Post-test & 143 & 27 & 21 \\
Mean (SD) & Pre-test & $61.69(16.7)$ & $22.79(2.12)$ & $16.85(1.95)$ \\
& Post-test_1 & $96.08(30.31)$ & $22.84(2.18)$ & $18.02(2.37)$ \\
t-test & post_1-pre & $7.56^{* *}$ & .18 & $3.07^{* *}$ \\
\hline
\end{tabular}

Keterangan: ${ }^{* *}$ significant $1 \%$

\section{Diskusi}

Pelatihan CTQI bertujuan untuk meningkatkan kompetensi guru BK dalam melakukan tugasnya sebagai konselor bagi pengembangan diri siswa. Pada studi 1 yang dilakukan ini, kompetensi ini diungkap melalui model asesmen $360^{\circ}$ (Bracken, Timmreck, Fleenor, \& Summers, 2001), self report, persepsi siswa, dan persepsi kepala sekolah terhadap kompetensi guru BK. Penelitian ini memperlihatkan hasil yang konsisten positif antara ketiga teknik asesmen yang dilakukan yaitu adanya peningkatan kompetensi yang berakibat terhadap persepsi positif yang diberikan oleh siswa dan kepala sekolah terhadap kompetensi guru BK.

Pelatihan CTQI ini dilakukan selama 10 hari di kelas dan dirancang dengan mengacu kepada taxonomy of significant learning (Fink, 2013) dijalankan dengan metode experiential learning (Kolb, 1984) sehingga memungkinkan guru peserta pelatihan belajar tentang ilmu pengetahuan dasar yang dibutuhkan oleh guru BK, berlatih cara mengaplikasikan 
teknik, mengkaitkan keterampilan yang baru didapat dengan kegiatan lain yang dilakukan di dalam kehidupan mereka sehari-hari, merasakan emosi diri dan emosi orang lain, mendapat feedback positif sehingga dapat memfasilitasi tumbuhnya learning how to learn (Fink, 2013).

Studi 2 dilakukan pada saat guru kembali ke sekolah melaksanakan tugasnya sebagai guru BK. Setelah mengaplikasikan keterampilan yang diperoleh di dalam melaksanakan tugas sehari-hari dengan disupervisi selama 12 minggu, guru menjadi semakin yakin akan kompetensi mereka sebagai guru BK. Hal ini juga dirasakan oleh siswa yang melaporkan bahwa jika selama ini menganggap guru BK hanya sebagai guru biasa namun setelah mereka pulang kembali ke sekolah siswa merasakan guru BK lebih bersahabat. Hal ini dapat disebabkan karena adanya peningkatan pengetahuan mengenai prinsip-prinsip perkembangan personal yang dialami individu khususnya remaja dan memahami proses perubahan perilaku. Bertambahnya pengetahuan dan perubahan sikap positif ini dapat memengaruhi personal development (Mustaffa, Nasir, Aziz, \& Mahmood, 2013) sehingga guru BK dapat menampilkan dirinya dengan lebih baik.

Hal yang perlu mendapat perhatian adalah hasil yang diperoleh dari data kepala sekolah, yang tidak melaporkan adanya perubahan ke arah positif. Hasil serupa juga diperoleh pada analisis yang dilakukan terhadap perubahan kompetensi guru non-BK (Ramdhani et al., 2012). Kepala sekolah yang sudah melihat adanya peningkatan kompetensi guru BK paska pelatihan in-class (studi 1) tidak merasakan adanya peningkatan efikasi diri konseling pada guru BK paska pendampingan (studi 2). Tidak adanya peningkatan kompetensi ini mungkin disebabkan karena guru BK lebih banyak berinteraksi dengan siswa dibandingkan dengan kepala sekolah.

Setelah mengikuti pelatihan, guru menyatakan lebih mampu mengenali emosi diri dan juga dapat mengenali reaksi emosi yang mungkin memberikan efek negatif dalam berinteraksi dengan orang lain. Peningkatan kompetensi emosi dan sosial ini mendukung hasil studi yang dilakukan oleh Adeyemo dan Adeleye (2008) bahwa peningkatan kompetensi guru dalam mengenali reaksi emosi memengaruhi efikasi diri, bahkan Easton et al. (2008) membuktikan bahwa kecerdasan emosi memberi sumbangan signifikan terhadap efikasi diri konseling. Di dalam pelatihan CTQI, di samping belajar keterampilan teknis untuk melayani siswa, guru BK juga difasilitasi dengan berbagai aktivitas yang menstimulasi pengembangan kompetensi personal dan sosial sehingga pengembangan kompetensi dapat terjadi secara menyeluruh. Di sini, guru BK menyadari dirinya sebagai seorang individu maupun sebagai seorang guru BK. Sebagai seorang individu, mereka akan mengenali kelebihan, kelemahan, dan reaksi-reaksi emosi diri dan emosi orang lain pada saat menjalani kehidupan sehari-hari. Sebagai seorang guru, mereka menyadari kembali komitmen profesi guru BK yang bertanggung jawab terhadap penciptaan lingkungan positif di sekolah agar siswa dapat berkembang dengan lebih baik. Komitmen terhadap profesi guru mungkin selama ini terlupakan karena rutinitas sehari-hari.

Lebih dari itu, pada saat guru menjalani aktivitas pengembangan kompetensi sosial mereka mendapat kesempatan untuk menyegarkan kembali keterampilan empati dan keterampilan sosial yang diejawantahkan di dalam berkomunikasi positif terutama dengan siswa dan rekan kerja. Kecerdasan emosi 
adalah sebuah konstruk unik yang inherent di dalam diri individu yang mendukung pencapaian karir profesional individu Easton et al., (2008).

Ucapan terima kasih

Studi ini dilakukan berdasarkan program Teacher Quality Im provement yang dibiayai oleh Reach Out to Asia, the Qatar Foundation melalui Titian Foundation.

\section{Daftar Pustaka}

Adeyemo, D. A., \& Adeleye, A. T. (2008). Emotional intelligence, religiosity and self-efficacy as predictors of psychological well-being among secondary school adolescents in Ogbomoso, Nigeria. Europe's Journal of Psychology, 4(1). doi: 10.5964/ejop.v4i1.423

Agustina, D. (2013, May 13). Ratusan pelajar SMA Watampone terlibat tawuran. Tribunews. Diunduh dari http://www.tribunnews.com/regio nal/2013/09/27/ratusan-pelajarsma-watam pone-terlibat-tawuran (diakses pada 13 Mei 2014)

Anderson, L. ., \& Krathwol, D. (2000). A taxonomy for learning, teaching, and assessing: A revision of Bloom's taxonomy of educational objectives. New York: Allyn \& Bacon.

Bandura, A. (1995). Self-efficacy in changing societies. Cambridge: Cambridge University Press.

Bandura, A. (2006). Guide for constructing self-efficacy scales. In F. Pajares \& T. Urdan (Eds.), Selfefficacy beliefs of adolescents (Vol. 5). Greenwich, CT: Information Age Pub.

Bempah, R. T. (2017, September). Forensik temukan kelainan di organ dalam siswa yang tewas duel ala gladiator. Kompas. Diunduh dari http://regional.kompas.com/read/2 017/09/16/16470031/kasus-duel-alagladiator-polisi-periksa-13-saksi

Bracken, D. W., Timmreck, C. W., Fleenor, J. W., \& Summers, L. (2001). 360 feedback from another angle. Human Resource Management, 40(1), 3-20. doi: $10.1002 / \mathrm{hrm} .4012$

Brown, D. R., \& Harvey, D. (2006). An experiential approach to organization development (Edisi ketujuh). New Jersey: Pearson-Prentice Hall.

Clore, G. L., \& Byrne, D. (1974). A reinforcement-affect model of attraction. In T. L. Huston (Ed.), Foundations of Interpersonal Attraction (pp. 143-170). Cambridge, MA: Academic Press.

Easton, C., Martin, W. E., \& Wilson, S. (2008). Emotional intelligence and implications for counseling selfefficacy: Phase II. Counselor Education and Supervision, 47(4), 218-232. doi: 10.1002/j.15566978.2008.tb00053.x

Eggleton, P. J. (1992). Motivation: A key to effective teaching. The Mathematics Educator, 3(2). Diunduh dari http://math.coe.uga.edu/TME/Issue s/v03n2/Eggleton.pdf

Epstein, S. (1998). Constructive thinking: The key to emotional intelligence. Westport, CT: Praeger Publisher.

Fink, L. D. (2013). Creating significant learning experiences: An integrated approach to designing college courses. San Fransisco: John Wiley \& Sons.

Goleman, D. (2000). Working with emotional intelligence. New York: Bantam.

Goleman, D. (2005). Emotional intelligence: Why it can matter more than IQ. New York: Bantam Books.

Greenaway, R. (2007). Dynamic debriefing. In M. Silberman (Ed.), The handbook of experiential learning (pp. 59-80). San Francisco, CA: Pfeiffer. 
Harvey, K., Churchill, D., Crawford, P., Brown, B., Mullany, L., Macfarlane, A., \& McPherson, A. (2008). Health communication and adolescents: What do their emails tell us? Family Practice, 25(4), 304-311. doi: $10.1093 / \mathrm{fam} \mathrm{pra} / \mathrm{cm} 029$

Kolb, D. (1984). Experiential education: Experience as the source of learning and development. New Jersey: PrenticeHall.

Kotter, J. P. (1996). Leading change. Brighton, MA: Harvard Business Press.

Larson, L M, Cardwell, T. R., \& Majors, M. S. (1996). Counselor burnout investigated in the context of social cognitive theory. In Annual meeting of the American Psychological Association, Toronto, Canada.

Larson, L. M, Clark, M. P., Wesely, L. H., Koraleski, S. F., Daniels, J. A., \& Smith, P. L. (1999). Videos versus role plays to increase counseling self-efficacy in prepractical trainees. Counselor Education and Supervision, 38(4), 237-248. doi: 10.1002/j.15566978.1999.tb00574.x

Larson, L. M, \& Daniels, J. A. (1998). Review of the counseling selfefficacy literature. The Counseling Psychologist, 26(2), 179-218. doi: $\underline{10.1177 / 0011000098262001}$

Leach, M. M., Stoltenberg, C. A. L. D., Mcneill, B. W., \& Eichenfield, G. A. (1997). Supervision self-efficacy and counselor development: Testing the integrated developmental model. Counselor Education and Supervision, 37(2), 115-124. doi: 10.1002/j.1556-6978.1997.tb00537.x

Low, G., \& Nelson, D. (2005). Emotional intelligence: The role of transformative learning in academic excellence. Texas Study of Secondary Education, 14(2), 41-44.

Lucas-Molina, B., Williamson, A. A.,
Pulido, R., \& Perez-Albeniz, A. (2015). Effects of teacher-student relationships on peer harassment: A multilevel study. Psychology in the Schools, 52(3), 298-315. doi: 10.1002/pits.21822

Melchert, T. P., Hays, V. L., Wiljanen, L. M., \& Kolocek, A. K. (1996). Testing models of counselor development with a measure of counseling selfefficacy. Journal of Counseling $\mathcal{E}$ Development, 74(6), 640-644. doi: 10.1002/j.1556-6676.1996.tb02304.x

Mustaffa, S., Nasir, Z., Aziz, R., \& Mahmood, M. N. (2013). Emotional intelligence, skills competency and personal development among counseling teachers. Procedia-Social and Behavioral Sciences, 93, 22192223.

doi: 10.1016/j.sbspro.2013.10.191

Nelson, D. B., \& Low, G. R. (2003). Emotional intelligence: Achieving academic and career excellence. Diunduh dari http://eprints.qums.ac.ir/1741/1/em otionally $\% 20$ intelligent $\% 20$ teacher. pdf

Niemiec, C. P., \& Ryan, R. M. (2009). Autonomy, competence, and relatedness in the classroom: Applying self-determination theory to educational practice. School Field, 7(2), 133-144. doi: $\underline{10.1177 / 1477878509104318}$

Ooi, P. B., Wan Jaafar, W. M. Bin, \& Baba, M. B. (2015). Relationship between sources of counseling self-efficacy and counseling self-efficacy among Malaysian school counselors. The Social Science Journal, 55(3), 369-376. doi: 10.1016/j.soscij.2017.05.005

Pertiwi, A., \& Cipta, A. (2012, May). Tawuran pelajar, tamparan bagi dunia pendidikan. Tempo. Diunduh dari http://www.tempo.co/read/fokus/2 
012/09/25/2587/Tawuran-PelajarTamparan-bagi-Dunia-Pendidikan Ramdhani, N. (2012). Menjadi guru inspiratif: aplikasi ilmu psikologi positif dalam dunia pendidikan. Jakarta: Titian Foundation.

Ramdhani, N., \& Ancok, D. (2013). Educational innovations for empowering teachers in acomplishing better education in Indonesia. QScience Proceedings, 2013(11). doi: 10.5339/qproc.2013.gic.11

Ramdhani, N., Ancok, D., Swasono, Y., \& Suryanto, P. (2012). Teacher quality improvement program: Empowering teachers to increasing a quality of Indonesian's education. Procedia - Social and Behavioral Sciences, 69, 1836-1841. doi: 10.1016/j.sbspro.2012.12.134

Raufelder, D., Scherber, S., \& Wood, M. A. (2016). The interplay between adolescents' perception of teacherstudent relationships and their academic self-regulation: does liking a specific teacher matter? Psychology in the Schools, 53(7), 736750. doi: $10.1002 /$ pits

Reese, R. J., Usher, E. L., Bowman, D. C., Norsworthy, L. A., Halstead, J. L., Rowlands, S. R., \& Chisholm, R. R. (2009). Using client feedback in psychotherapy training: An analysis of its influence on supervision and counselor selfefficacy. Training and Education in Professional Psychology, 3(3), 157-168. doi: doi: 10.1037/a0015673

Rimm-kaufman, S., \& Sandilos, L. (2011). Im proving students ' relationships with teachers to provide essential supports for learning, 1-30. Diunduh dari http://www.apa.org/education/k12/ relationships.aspx

Rofiq, A. (2014). Siswa kelas 5 SD dipukuli kakak kelas hingga tewas karena senggol minuman. Detik. Diunduh dari

http://news.detik.com/read/2014/05 L04/155341/2572684/10/siswa-kelas5-sd-dipukuli-kakak-kelas-hinggatewas-karena-senggolminuman?nd771104bcj

Sasongko, A. (2014, May 13). Siswi SMP Tabanan gantung diri setelah UN. Republika. Diunduh dari http://www.republika.co.id/berita/ pendidikan/eduaction/14/05/06/n55 evj-siswi-smp-tabanan-gantungdiri-setelah-un

Schiele, B. E., Weist, M. D., Youngstrom, E. A., Stephan, S. H., \& Lever, N. A. (2014). Counseling self-efficacy, quality of services and knowledge of evidence-based practices in school mental health. The Professional Counselor, 4(5), 467-480. doi: doi: 10.15241/bes.4.5.467

Seligman, M. E. P. (2004). Authentic happiness: Using the new positive psychology to realize your potential for lasting fulfillment. New York: Simon and Schuster.

Silberman, M. (2007). The handbook of experiential learning. San Francisco: John Wiley \& Sons, Inc. doi: 10.1111/j.1467-8535.2008.00925 10.x

Stoltenberg, C. D., \& McNeill, B. W. (2011). IDM supervision: An integrative developmental model for supervising counselors and therapists. London: Routledge.

Sulkowski, M. L., \& Simmons, J. (2018). The protective role of teacherstudent relationships against peer victimization and psychosocial distress. Psychology in the Schools, 55(2), 137-150. doi: 10.1002/pits. 22086

Sutton, R. E., \& Wheatley, K. F. (2003). Teachers' emotions and teaching: A review of the literature and directions for future research. 
Educational Psychology Review, 15(4), 327-358. doi: 10.1023/A:1026131715856

Tang, M., Addison, K. D., LaSure-Bryant, D., Norman, R., O'Connell, W., \& Stewart-Sicking, J. A. (2004). Factors that influence self-efficacy of counseling students: An exploratory study. Counselor Education and Supervision, 44(1), 7080. doi: 10.1002/j.15566978.2004.tb01861.x

Ümmet, D. (2017). Structural relationships among counselling self-efficacy, general self-efficacy and positive-negative affect in psychological counsellor candidates. Educational Sciences: Theory \& Practice, 17(6), 1875-1892. doi: $10.12738 /$ estp.2017.6.0180

Urbani, S., Smith, M. R., Maddux, C. D., Smaby, M. H., Torres-Rivera, E., \& Crews, J. (2002). Skills-based training and counseling selfefficacy. Counselor Education and Supervision, 42(2), 92-106. doi: 10.1002/j.1556-6978.2002.tb01802.x 